Original Research Paper

\title{
Population and Behavior Surveys of Long-Tailed Macaque (Macaca fascicularis) in the Old Town, Lopburi Province
}

\author{
${ }^{1}$ Duangjai Boonkusol, ${ }^{2}$ Pornchai Sanyathitiseree, ${ }^{3}$ Suporn Thongyuan and ${ }^{1}$ Nantana Jangsuwan \\ ${ }^{1}$ Department of Biology, Faculty of Science and Technology, \\ Thepsatri Rajabhat University, Lopburi, Thailand \\ ${ }^{2}$ Department of Large Animal and Wildlife Clinical Science, Faculty of Veterinary Medicine, \\ Kasetsart University, Nakornpathom, Thailand \\ ${ }^{3}$ Department of Veterinary Public Health, Faculty of Veterinary Medicine, \\ Kasetsart University, Nakornpathom, Thailand
}

\author{
Article history \\ Received: 10-02-2018 \\ Revised: 21-03-2018 \\ Accepted: 07-05-2018 \\ Corresponding Author: \\ Duangjai Boonkusol \\ Department of Biology, Faculty \\ of Science and Technology, \\ Thepsatri Rajabhat University, \\ Lopburi, Thailand \\ Tel.: +66 899929368 \\ Email: ngamsomd@gmail.com
}

\begin{abstract}
Long-tailed macaque (Macaca fascicularis) in the old town, Lopburi province rapid increase in their number as well nuisance activities. Strategies and management plans of Lopburi province, Thailand need to be developed and enacted in order to remedy some of the problems occurring in human-macaque interface zones. Therefore, this study aimed to investigate the macaque number and behavior, a survey on their population number and behavior was conducted from November, 2014 to May, 2015. Population estimation of long-tailed macaque was done by surveying seven macaque groups in the old town, Lopburi province: Prang Sam Yot shrine (GR1) Malai Rama theatre (GR2), Van station (GR3), Chayowanich building (GR4), Muang Thong hotel (GR5), Manora market (GR6) and Sengheng building (GR7). The identified macaque groups were visited during dusk or dawn and visual counts of each group were made carefully from close distance. One-way ANOVA, followed by Least Significant Difference (LSD) method was used for analysis of differences in macaque population number. Total estimated macaque population of seven groups range was between 1,920 and 2,080. Group size ranged from 70 to 700 individuals. Male and female sex ratio was estimated at 1:1.3. Behavior of M. fascicularis was observed by using scan sampling method for 216 hours during November, 2014 to May, 2015. The high levels frequency of behavior between macaque and macaque was feeding (20\%) and inactive (29\%). Food-related interaction (32\%) was the highest frequency of behavior between macaque and human. Results suggested that factors related to macaque number and behavior for could be related to dietary resources. Moreover, feeding, playing, agonistic, moving, defecation and foodrelated interaction behavior were high frequency at period of 9 am. Conflicting, aggression and vocalization behavior were shown the most percentage of behavior frequency at $10 \mathrm{am}$ and $4 \mathrm{pm}$. This data will be useful for management of respective locales was recommended to formulate practical strategies to avoid or decrease the interaction between macaque and human. The macaque population needs to be monitored and studied in depth to better understand their dynamics and behavioral adaptations to this old town.
\end{abstract}

Keywords: Long-Tailed Macaque, Urban Macaque Population, Macaque Human Behavior, Synanthropy, Thailand 


\section{Introduction}

Long-tailed macaques (Macaca fascicularis) are the most frequently seen species among the thirteen species of primates in Thailand (Malaivijitnond et al., 2005) and they were recently reported at 91 locations (Malaivijitnond et al., 2009). They have been frequently seen on the forest periphery and at recreation parks, tourist attraction sites, temples and other areas nearby human settlements (Aggimarangsee, 1992; Fooden, 1995; Malaivijitnond and Hamada, 2008). Lopburi is renowned monkey city of Thailand due to a population of long-tailed macaques that extensively interfaces with the people. The exact history of this monkey occupancy is not officially documented, but Fooden reported Lopburi human residents stating that the monkeys were thought to have descended to the shrine area from adjacent forests at least 50-60 years before his observations in 1967 (Fooden, 1971). If so, they have been in the city for over 100 years. Preliminary data from an intensive investigation of the human-longtailed macaque interface at Lopburi from interviews and direct field observations revealed that macaques in old town, Lopburi are associated to religious systems and macaques are a significant source of revenue as a tourist attraction (Malaivijitnond et al., 2005; Malaivijitnond and Hamada, 2008).

The old town is the area that monkey promoted for tourism. The benefit of tourism has generated a mutualistic relationship between the local communities and the monkeys. People feeding attracted monkey to the site, while the macaques are responsible for bringing in tourists that provide revenue to the local community (Wheatley and Putra, 1994; 1995). Local people make a living as photographers, tour guides and merchants. The goods and services provided include food for feeding the monkeys, photographs of tourists with monkeys, guided tours and protection from aggressive monkeys, retrieval of items taken by monkeys, local artwork, souvenirs and refreshments. In Lopburi, annual celebrations occur for the monkeys that bring in large crowds of people and sponsors. Moreover, the local tourist industry utilizes the macaques as their main attraction, having monkey hotels, monkey restaurants and a monkey-themed train station.

Macaques in Lopburi, Thailand inhabit the downtown regions and walk along the streets as freely as the people living (Malaivijitnond et al., 2005; Malaivijitnond and Hamada, 2008). Due to the urban nature of Lopburi, there is very little vegetation within the macaqueinhabited areas. The macaques are almost entirely dependent on human provisioning for their survival and all of the macaques in Lopburi receive provisioning from people. As a result, there is a very close interface between people and macaques, perhaps one of the most intense interfaces on earth. People are highly affected by macaques in Lopburi and so measures are needed to properly manage this population. People use a variety of short-term tactics to deter macaques and the preferred tools for monkey deterrence appear to be sling-shots, toy machine guns and sticks. To help alleviate conflict, people in some sites build barriers and use fencing or caging to block access by the monkeys into their homes and sometimes macaques are culled or removed at times when conflict becomes too great for the affected community. Macaques also face other dangers specific to human landscapes. They are at risk of human aggression, they move around and utilize electrical wiring for travel and frequently move on roads, presenting the risk of injury and fatality. In Singapore and Hong Kong, automobile accidents represent a large proportion of mortality (Sha et al., 2009a).

The estimated population size and number of longtailed macaques groups in old town, Lopburi was recorded by (Watanabe et al., 2007) who recorded five troops located in the old city area and around Prang Sam Yot, comprising 850-1,100 individuals within a $300 \times 400 \mathrm{~m}^{2}$ area. Malaivijitnond and Hamada (2008) revealed that there were approximately 900-1,150 individuals in the old city area, Lopburi from counting, while people personally estimated a larger number range between 1,500-4,000 individuals from interview answers regarding the macaque population. Population studies of primates and other mammal species are important to document their current status and obtain information about their densities, group structure and population dynamics (Defler and Pintor, 1985). Such information is helpful in assessing the suggested management of respective locales that was recommended to formulate practical strategies to avoid or decrease the interaction between macaque and human. Therefore, this study focused on population survey and long term daily activity of long-tailed macaque (M. fascicularis) in the old town, Lopburi to understand their activities throughout a day and interaction with human interface environment.

\section{Materials and Methods}

Study site: This research was conducted in the old town, Lopburi, Thailand. It is located $154 \mathrm{~km}$ north of Bangkok. Study area contains historical structures, concrete buildings, Thai traditional house, modern house, market, government official building, hotel, temples, shrine, street, railway and faculties. Macaque groups of studies were divided according to their lair (place to sleep) into seven lair areas: (1) Prang Sam Yot shrine, (GR1) (1448'10"N 100 $\left.366^{\prime} 50^{\prime \prime} \mathrm{E}\right)$ and (2) building included 7 groups as follows: Malai Rama theatre (GR2) (14\%48'5"N 100 $\left.37^{\prime} 1 " \mathrm{E}\right)$, Van station (GR3)

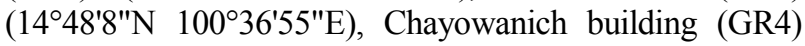
$\left(14^{\circ} 48^{\prime} 10^{\prime \prime} \mathrm{N} 100^{\circ} 36^{\prime} 54^{\prime \prime E}\right.$ ), Muang Thong hotel (GR5) $\left(14^{\circ} 48^{\prime} 10^{\prime \prime} \mathrm{N} 100^{\circ} 36^{\prime} 53^{\prime \prime} \mathrm{E}\right)$, Manora market (GR6) $\left(14^{\circ} 48^{\prime} 9^{\prime \prime N} 100^{\circ} 36^{\prime} 46^{\prime \prime E}\right)$ and Sengheng building (GR7) $\left(14^{\circ} 48^{\prime} 3^{\prime \prime N ~} 100^{\circ} 36^{\prime} 49^{\prime \prime} \mathrm{E}\right)$. The locations and geographical coordinates of studied sites were shown Fig. 1. 


\section{Population Study}

The population of macaque in the old town, Lopburi was studied and counted. Each macaque group was identified through the sleeping places. Map of the study site at the old town, Lopburi was shown in Fig. 1. Each individual was confirmed as belonging to a certain group by its movement in tandem with the movement of the group. This was to avoid observation errors associated with assigning individuals to more than one group. There are four criteria in ascertaining whether an individual belongs to a particular group, which we used in this study. These are (1) observation through the tandem movements; (2) determining the occurrence of dispersal among individuals; (3) identifying whether spatial relationships influenced the individual to stay in a group; and (4) determining whether the formation of group is only for a short period. Identification of individuals used the following criteria: adult males were recognized by their body size and presence of testicles, while adult females were also recognized by body size, presence of vulva, or if holding an infant. Juveniles and infants were identified by their size and independency from the mother. Juveniles and infants were not identified their sex due to fast movement, dense monkey and distances of the groups.

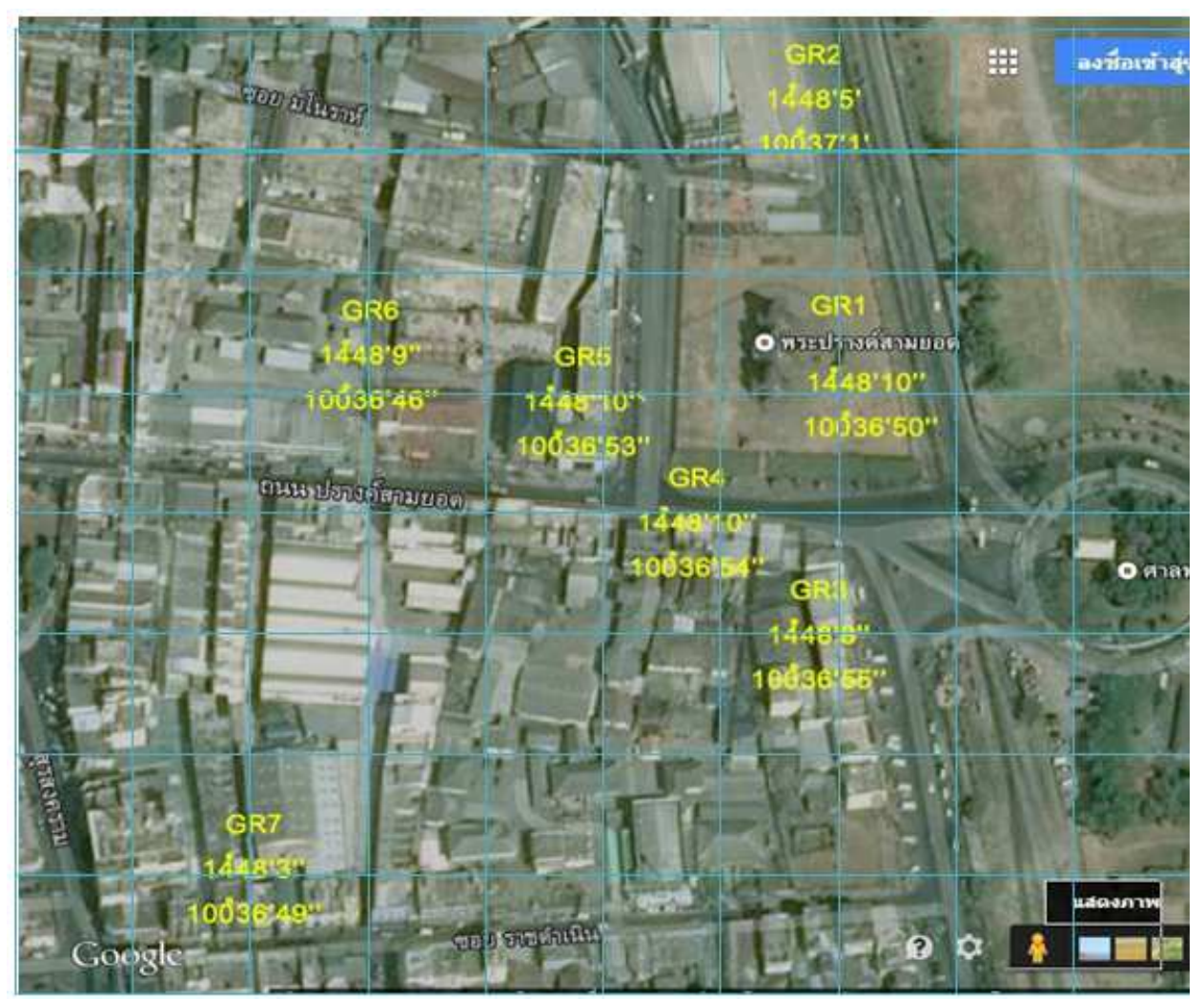

Fig. 1: Location names (GR1-GR7) and geographical coordinates studies sites at the old town, Lopburi (Google Earth, N 1448', E 100³6')

Table 1: Macaque-macaque behavior recorded during the study (Modified from Aggimarangsee, 1992)

\begin{tabular}{|c|c|}
\hline Behavior categories & Description \\
\hline 1. Feeding (FD) & $\begin{array}{l}\text { Bringing food into mouth, keep at bulge of cheek, bite, chew, swallow, lick material and other things that is } \\
\text { neither from nature or human, drinking water, seeking food, include seeking food from garbage, receiving } \\
\text { food from human, seizing food from other monkeys }\end{array}$ \\
\hline 2. Inacti & ting or lie down without the closed eyes or with the closed eyes on the block, tree, ground, or other places \\
\hline 3. Pla & ne another and mock fighting \\
\hline 4. Groo & Cleaning itself or cleaning among monkeys using mo \\
\hline 5. Agonis & Threatening, fighting within troop/between troop, jumping at and pulling, chasing, biting, threate \\
\hline 6. Sexual (SE) & $\begin{array}{l}\text { Smelling of female genitalia. Female monkey turned its genitalia to male monkey and copulation with and without } \\
\text { penis insertion }\end{array}$ \\
\hline 7. Moving (MV) & Walking, running, climbing, swing, jumping, getting in a car and train, movement accompanies with human \\
\hline 8. Defecation (DF) & Lifting tail, swagger, going to stool and urinating \\
\hline 9. Maternal care (MC) & Taking care of child, breast-feeding and cleaning child \\
\hline
\end{tabular}


Table 2: Macaque - human behavior recorded during the study (Modified from Md-Md-Zain et al., 2010; Perveen et al., 2014)

\begin{tabular}{ll}
\hline Behavior categories & Description \\
\hline 1. Food-related interaction (FI) & $\begin{array}{l}\text { Begging for food, taken food by force from human and running off with it, receiving food from } \\
\text { tourist /people in the community, tourist /people throw the food to them from far away. }\end{array}$ \\
2. Conflicting (CF) & $\begin{array}{l}\text { Disagreement among various behaviors of human and monkey such as damaging property, } \\
\text { taking food or other belonging of human, entering into human's residence } \\
\text { Threatening or chasing human }\end{array}$ \\
3. Aggression (AS) & $\begin{array}{l}\text { High pitched sound like grunts, greeting, contact, mating, distress calls, whistling and } \\
\text { screaming etc. }\end{array}$ \\
4. Vocalization (VL) & The approach between human and monkey in order to play or take a photograph \\
5. Neutral (NT) &
\end{tabular}

\section{Behavioral Study}

Macaque behaviors of seven groups were observed. Observations of macaque behavior were conducted from November, 2014 to May, 2015. Full day observations from dawn to dusk were made, using scan sampling methods (Altmann, 1974). The observation was stopped when the weather was cloudy or rainy. In this survey, we observed both behavior among longtailed macaques (Table 1) and behavior between humans and long-tailed macaques (Table 2). Behaviors frequencies were recorded.

\section{Data Analysis}

The densities were calculated using the following equation: $\mathrm{D}=\Sigma \mathrm{n} / \mathrm{m}^{2}$, where: $\mathrm{D}=$ density; $\Sigma \mathrm{n}=$ the sum of the total individuals observed and $\mathrm{m}^{2}=$ the longitude (meter) multiplied by the width (meter). One wayANOVA, followed by Least Significant Difference (LSD) method was used for analysis of differences in macaque population number. $\mathrm{P}$ value less than 0.05 $(p<0.05)$ was considered significant. Behaviors results of were reported as frequencies percentage.

\section{Results}

\section{Population Study}

During the population survey of old town Lopburi, seven monkey groups were located at different places. Locations of the seven groups are shown in Fig. 2. Their total estimated population ranged between 1,920 and 2,080. Maximum macaque numbers (700 individuals/group) were recorded from Prang Sam Yot shrine, whereas only 70-80 individuals were observed in Manora market (Table 3). The observed groups revealed their own home range and some groups found overlapped with others.

Long-tailed macaques in all seven groups were counted directly with a mean \pm SD of $64.4 \pm 37.2$ adult females, 48.6 \pm 21.18 adult males, $143.3 \pm 127.8$ juveniles, $33.4 \pm 25.5$ infants and $72.9 \pm 43.6$ unidentified individuals. Male/female sex ratio was estimated at 1:1.3 (Table 4).

\section{Behavioral Study}

Observation for 216 hours during November, 2014 to May, 2015, behavior between macaque and macaque was classified into nine categories as shown in Table 1. The result in Fig. 2 showed the frequency percentages of macaques and macaque behaviors. The two high frequency percentages of their behaviors throughout a day were feeding and inactive habits, while maternal care, sexual and agonistic behaviors were in only a small portion of daily behaviors. Feeding, playing, agonistic and defecation were shown the most percentage of behavior frequency at 9 am (Fig. 4). Feeding and inactivity behaviors were the same with all study groups. The inactivity or resting behavior occurred when food sources were limited. During the observation all of seven groups these macaques came to close human when food as available. The long-tailed macaques in Lopburi was accustomed to human food especially the sweetened ones such as Yakult, soft drinks with basil, ice cream, junk food, carbonated soft drinks.

Behavior between macaque and human was classified into five categories as shown in Table 2. Observation for 216 h during November, 2014 to May, 2015. Foodrelated interaction $(32 \%)$ was the highest frequency of behavior between macaque and human. Conflicting frequencies of macaques in seven groups were $11 \%$ (Fig. 3). There is a variation in the frequencies of conflict-related behavior across the study sites. This might be affected by factors such as the distance from human residences to macaque and also how effective the garbage collecting schedule. The highest percentage of behavior frequency between macaque and human of seven groups in old town, Lopburi at 9 am and 4 pm was food-related interaction (Fig. 5). Conflicting, aggression and vocalization were shown the most percentage of behavior frequency at 10 am and $4 \mathrm{pm}$. Seven macaque groups would spend multiple hours foraging in an area close to food resources. Interaction of $M$. fascicularis and human has been increased due to the tremendous increase in the populations of both species in the old town, Lopburi province. M. fascicularis has been disturbed due to human activities. In turn, $M$. fascicularis re-emerged with an effective and high-level reaction to human population. Behavior observations suggest interactions appear to differ in distinct areas and between various participants. The interactions between tourists and macaques are intense, close in contact and brief, while the interactions between macaques and locals appear to exhibit little direct contact. 
Table 3: Population size range in each the group of long-tailed macaques

\begin{tabular}{llll}
\hline Monkey group & Area $\left(\mathrm{m}^{2}\right)$ & Population size range & Relative abundance $\left(\right.$ ind. $\left./ \mathrm{m}^{2}\right)$ \\
\hline Prang Sam Yot shrine (GR1) & 7,311 & $680-700$ & $0.093-0.096$ \\
Malai Rama theatre (GR2) & 6,730 & $350-400$ & $0.052-0.059$ \\
Van station (GR3) & 2,812 & $90-100$ & $0.032-0.035$ \\
Chayowanich building (GR4) & 14,000 & $280-300$ & $0.020-0.021$ \\
Muang Thong hotel (GR5) & 10,000 & $140-150$ & $0.014-0.015$ \\
Manora market (GR6) & 10,000 & $70-80$ & $0.007-0.008$ \\
Sengheng building (GR7) & 20,666 & $310-350$ & $0.015-0.017$ \\
Total population & & $1,920-2,080$ & \\
\hline
\end{tabular}

Table 4: Group composition of long-tailed macaques

Age and sex composition (Mean \pm SD)

\begin{tabular}{llllll} 
Monkey group & $\mathrm{M}$ & $\mathrm{F}$ & $\mathrm{J}$ & $\mathrm{I}$ & $\mathrm{NI}$ \\
\hline Prang sam yot shrine (GR1) & $70.2 \pm 2.5^{\mathrm{a} 1}$ & $100 \pm 3.5^{\mathrm{a} 2}$ & $423.6 \pm 10.5^{\mathrm{a} 3}$ & $89.4 \pm 1.9^{\mathrm{a} 4}$ & $126.4 \pm 9.0^{\mathrm{a} 5}$ \\
Malai rama theatre (GR2) & $71.6 \pm 6.6^{\mathrm{a} 1}$ & $96 \pm 7.9^{\mathrm{a} 2}$ & $95.6 \pm 13.7^{\mathrm{b} 2}$ & $53.2 \pm 8.2^{\mathrm{b} 3}$ & $126.4 \pm 14.0^{\mathrm{a} 4}$ \\
Van station (GR3) & $31 \pm 3.1^{\mathrm{b} 1}$ & $32.8 \pm 5.2^{\mathrm{b} 1}$ & $54.4 \pm 0.6^{\mathrm{c} 2}$ & $15.8 \pm 3.5^{\mathrm{c} 3}$ & $29.8 \pm 6.9^{\mathrm{b} 4}$ \\
Chayowanich building (GR4) & $73 \pm 9.6^{\mathrm{a} 1}$ & $119 \pm 11.1^{\mathrm{a} 2}$ & $146.2 \pm 7.4^{\mathrm{d} 3}$ & $32.6 \pm 2.8^{\mathrm{d} 4}$ & $102.4 \pm 6.5^{\mathrm{c} 5}$ \\
Muang thong hotel (GR5) & $35 \pm 8.5 .8^{\mathrm{c} 1}$ & $41.6 \pm 2.2^{\mathrm{c} 1}$ & $48.2 \pm 2.9^{\mathrm{c} 2}$ & $13.2 \pm 2.9^{\mathrm{c} 3}$ & $49 \pm 11.9^{\mathrm{d} 2}$ \\
Manora market (GR6) & $29.6 \pm 2.3^{\mathrm{bc} 1}$ & $31 \pm 5.8^{\mathrm{b}}$ & $41.6 \pm 2.3^{\mathrm{c}}$ & $9.8 \pm 0.5^{\mathrm{ce}}$ & $16.6 \pm 5.0^{\mathrm{e}}$ \\
Sengheng building (GR7) & $30 \pm 2.9^{\mathrm{b} 1}$ & $30.4 \pm 6.1^{\mathrm{b} 1}$ & $193.4 \pm 11.9^{\mathrm{e} 2}$ & $19.6 \pm 8.2^{\mathrm{c} 3}$ & $60.2 \pm 7.3^{\mathrm{d} 4}$ \\
Total average & $48.6 \pm 21.2$ & $64.4 \pm 37.2$ & $143.3 \pm 127.8$ & $33.4 \pm 25.5$ & $72.9 \pm 43.6$ \\
\hline M A A & & J & &
\end{tabular}

$\mathrm{M}=$ Adult male, $\mathrm{F}=$ Adult female, $\mathrm{J}=$ juvenile, $\mathrm{I}=$ infant, $\mathrm{NI}=$ not identified, $\mathrm{SD}=$ Standard deviation; Values with different superscript letters $(\mathrm{a}, \mathrm{b}, \mathrm{c}, \mathrm{d}, \mathrm{e})$ in each column and different superscript numbers $(1,2,3,4,5)$ in each line are significantly different $(\mathrm{p}<0.05)$

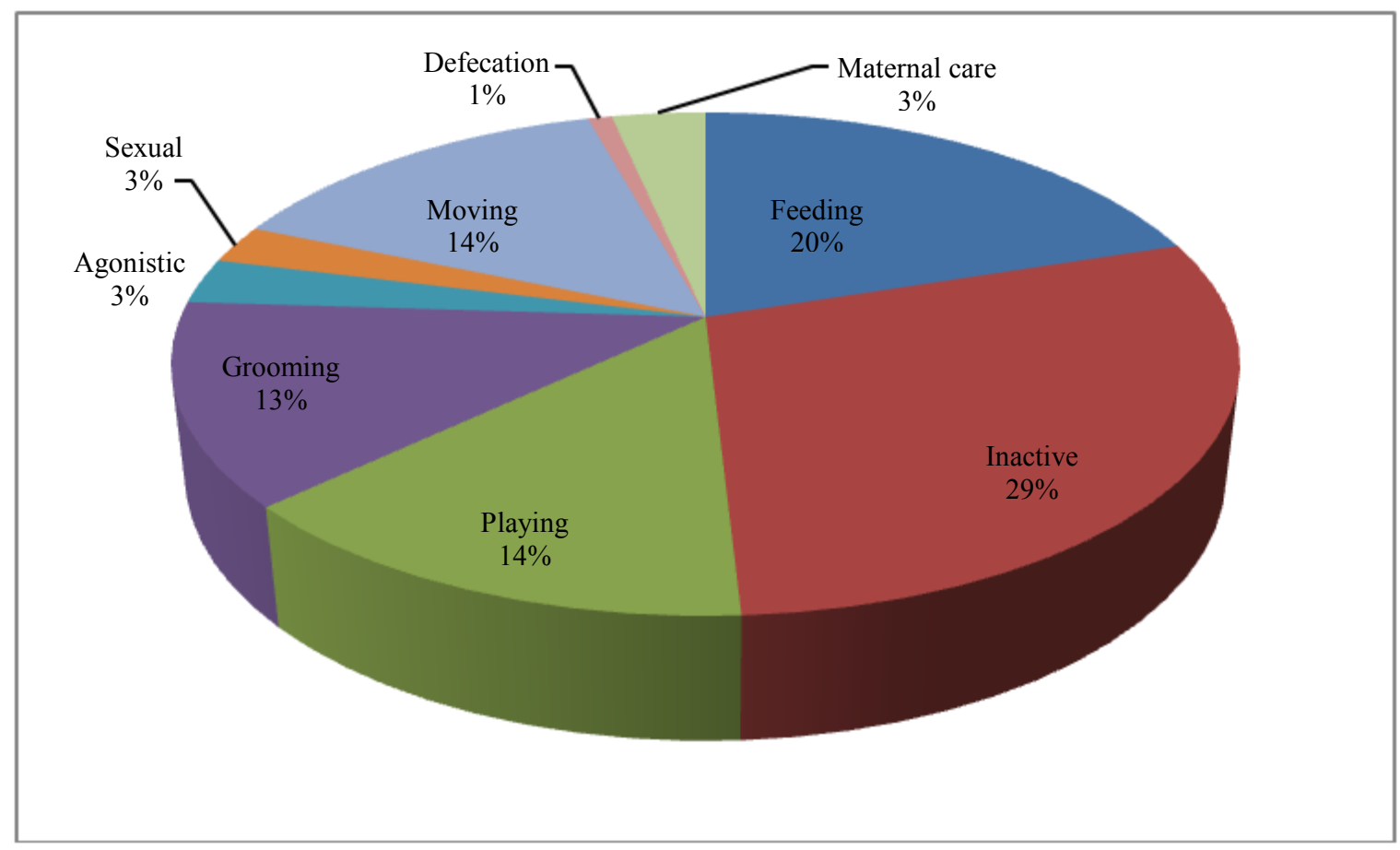

Fig. 2: Distribution of behavior between macaque and macaque of seven groups in old town, Lopburi from observation for 216 hours during November, 2014 to May, 2015. Data (\%) for each behavior are: inactive: 29; feeding: 20; moving: 14; playing: 14; grooming: 13; maternal care: 3; sexual: 3; agonistic: 3; defecation: 1 


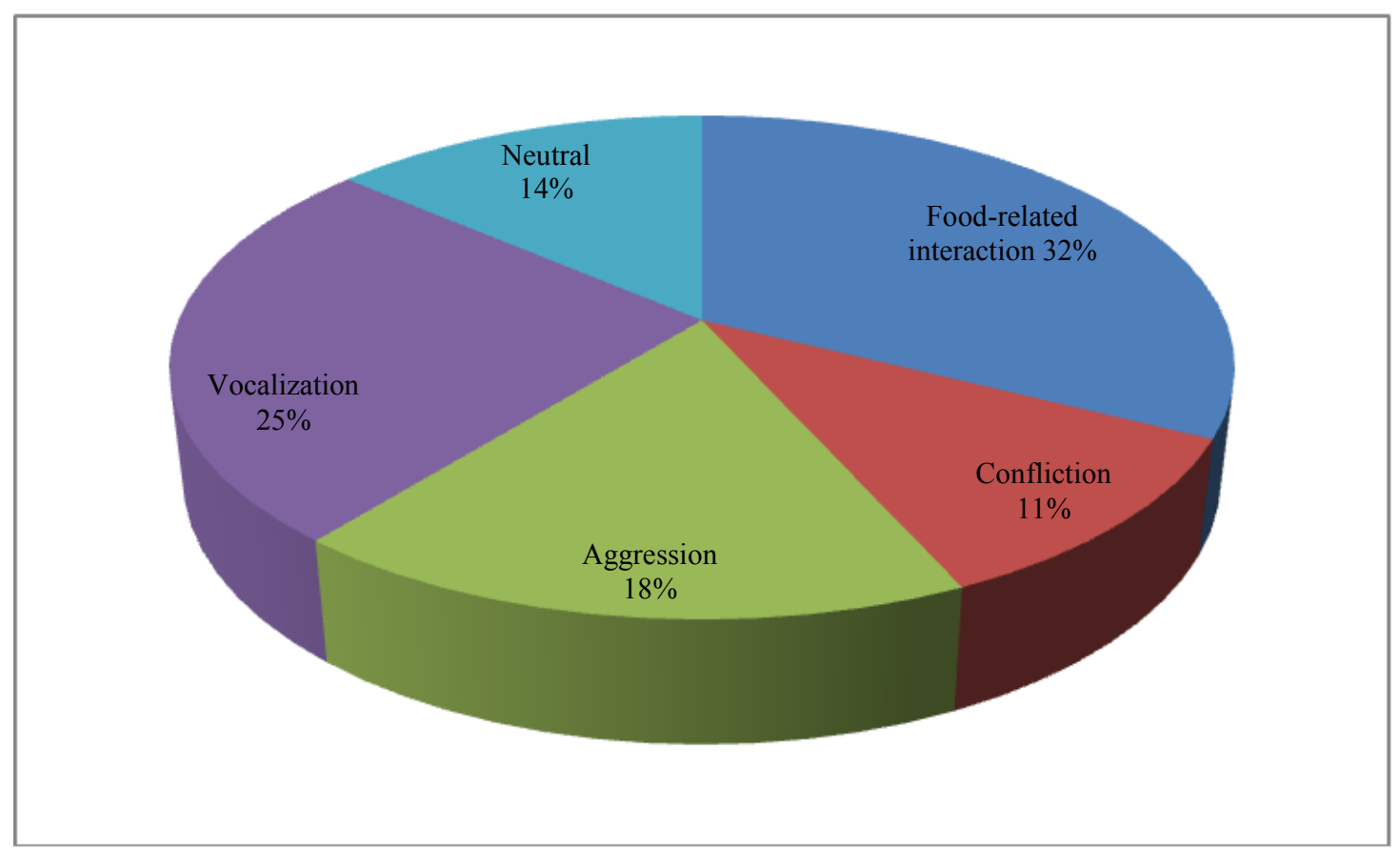

Fig. 3: Frequency percentage of behavior between macaque and human of seven groups in old town, Lopburi from observation for 216 hours during November, 2014 to May, 2015. Data (\%) for each behavior are: food-related interaction: 32; vocalization: 25; aggression: 18; neutral: 14; conflicting: 11
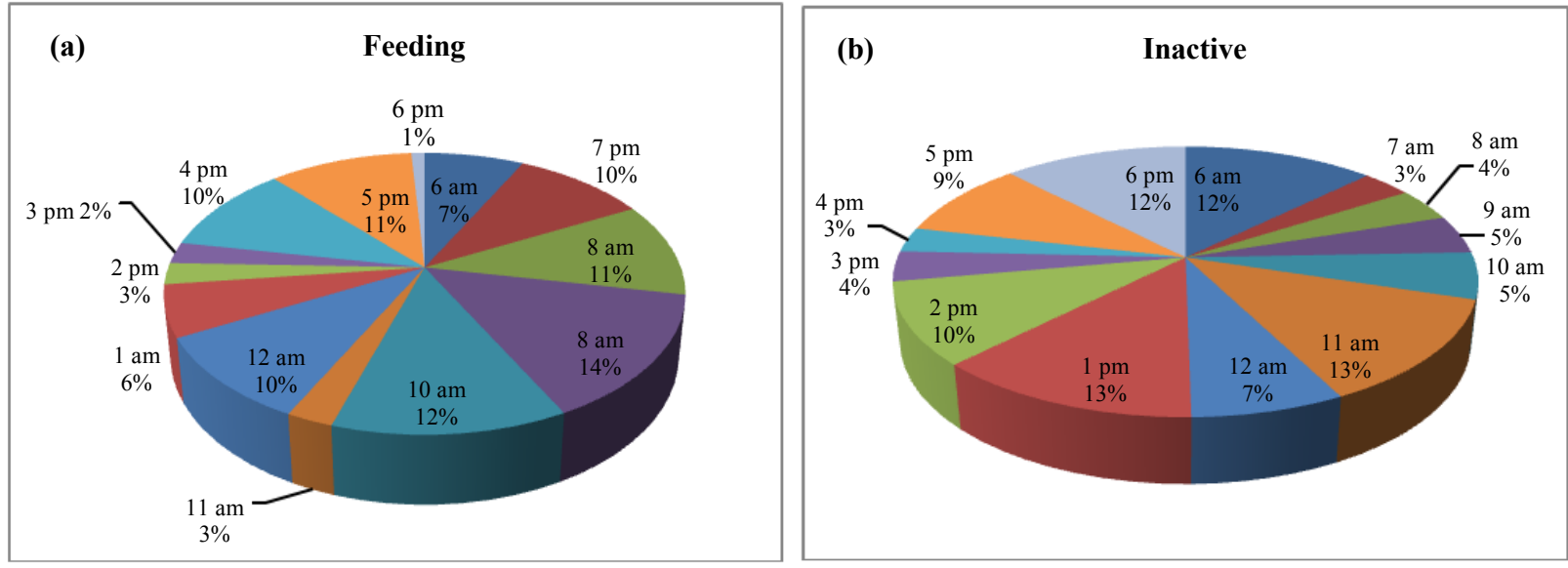

(c)

Playing

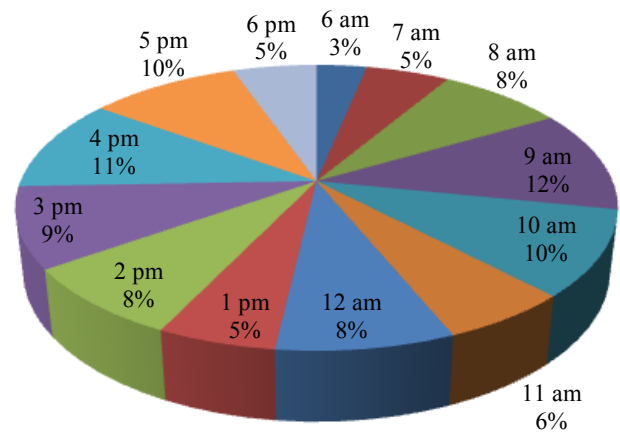

(d)

\section{Grooming}

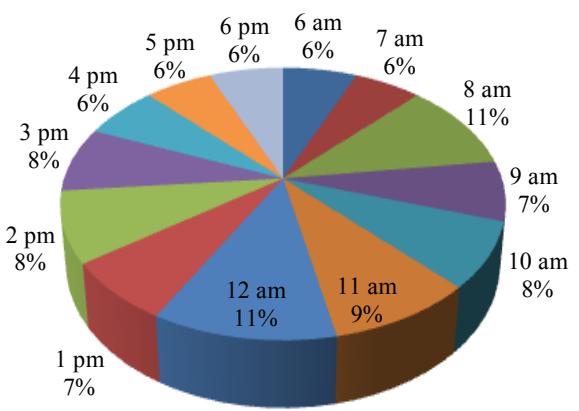



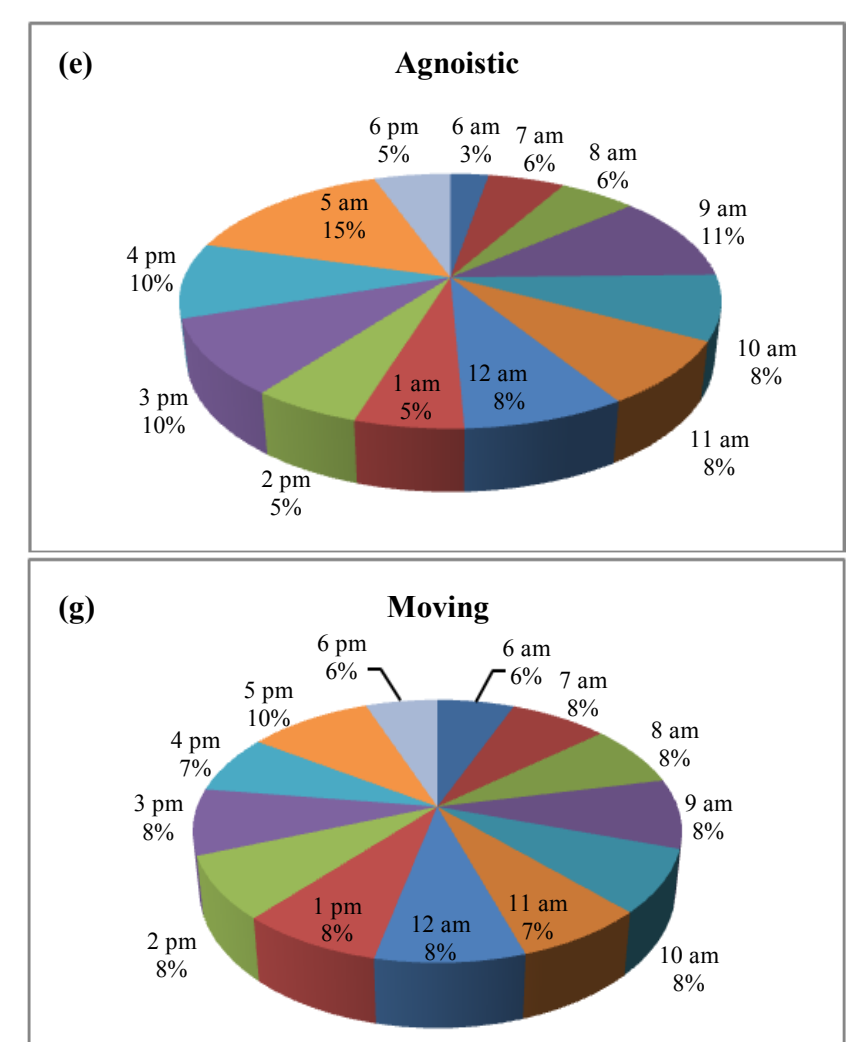

(f)

\section{Sexual}

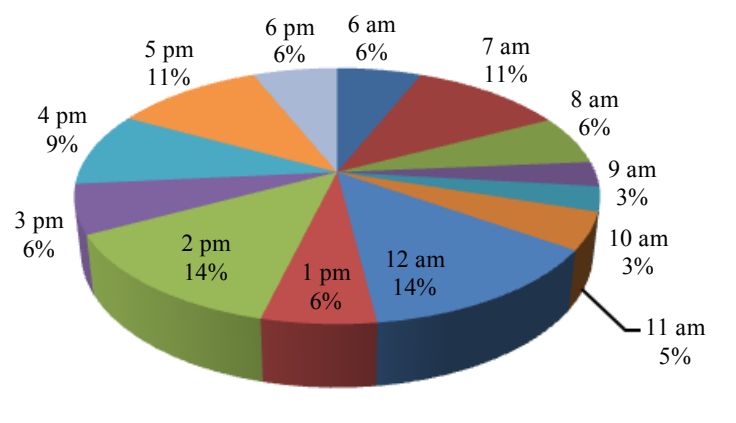

(h)

Defecation

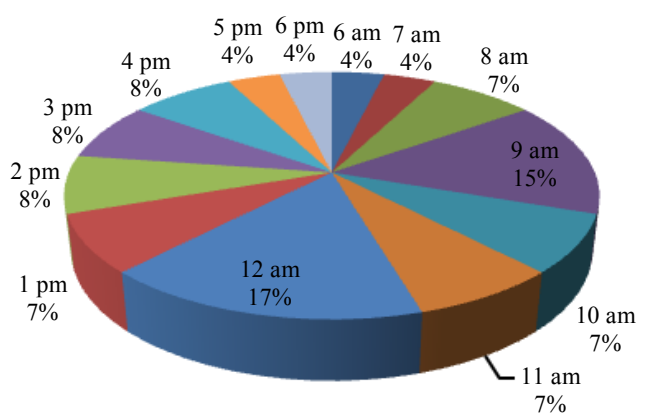

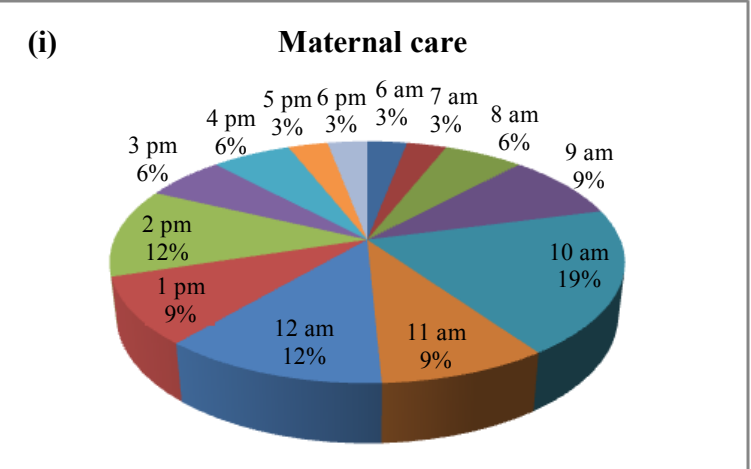

Fig. 4(a-i): Frequency percentage of behavior between macaque and macaque: (a) Feeding, (b) Inactive, (c) Playing, (d) Grooming, (e) Agonistic, (f) Sexual, (g) Moving, (h) Defecation and (i) Maternal care at different period of a day
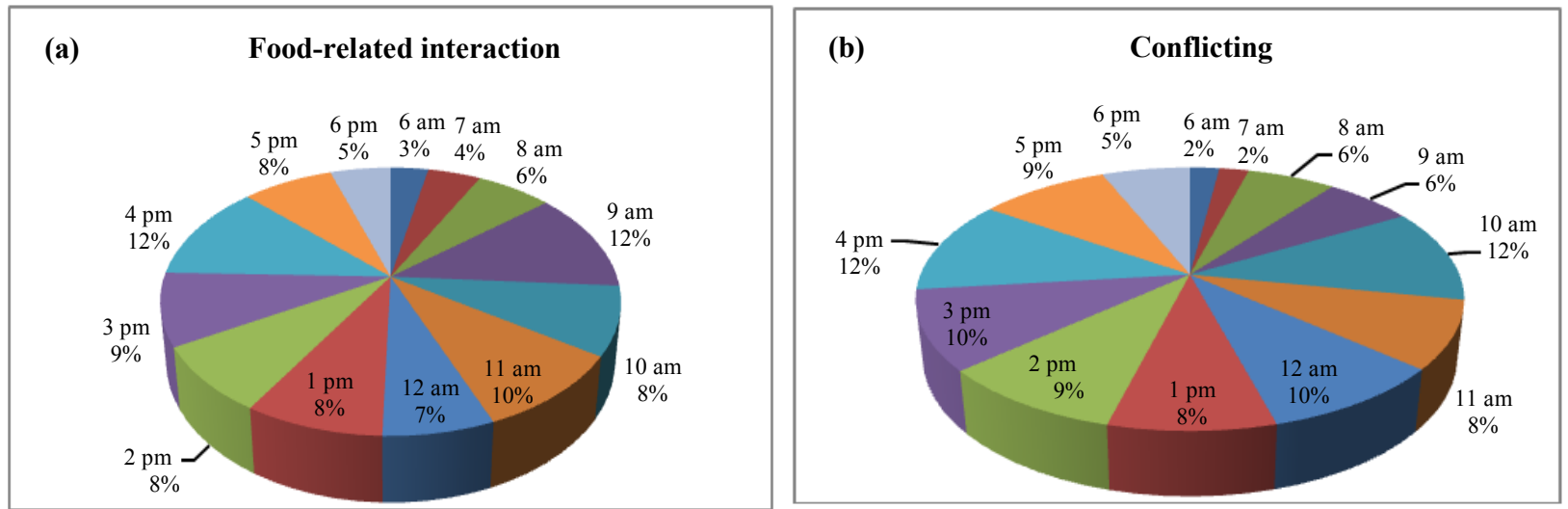


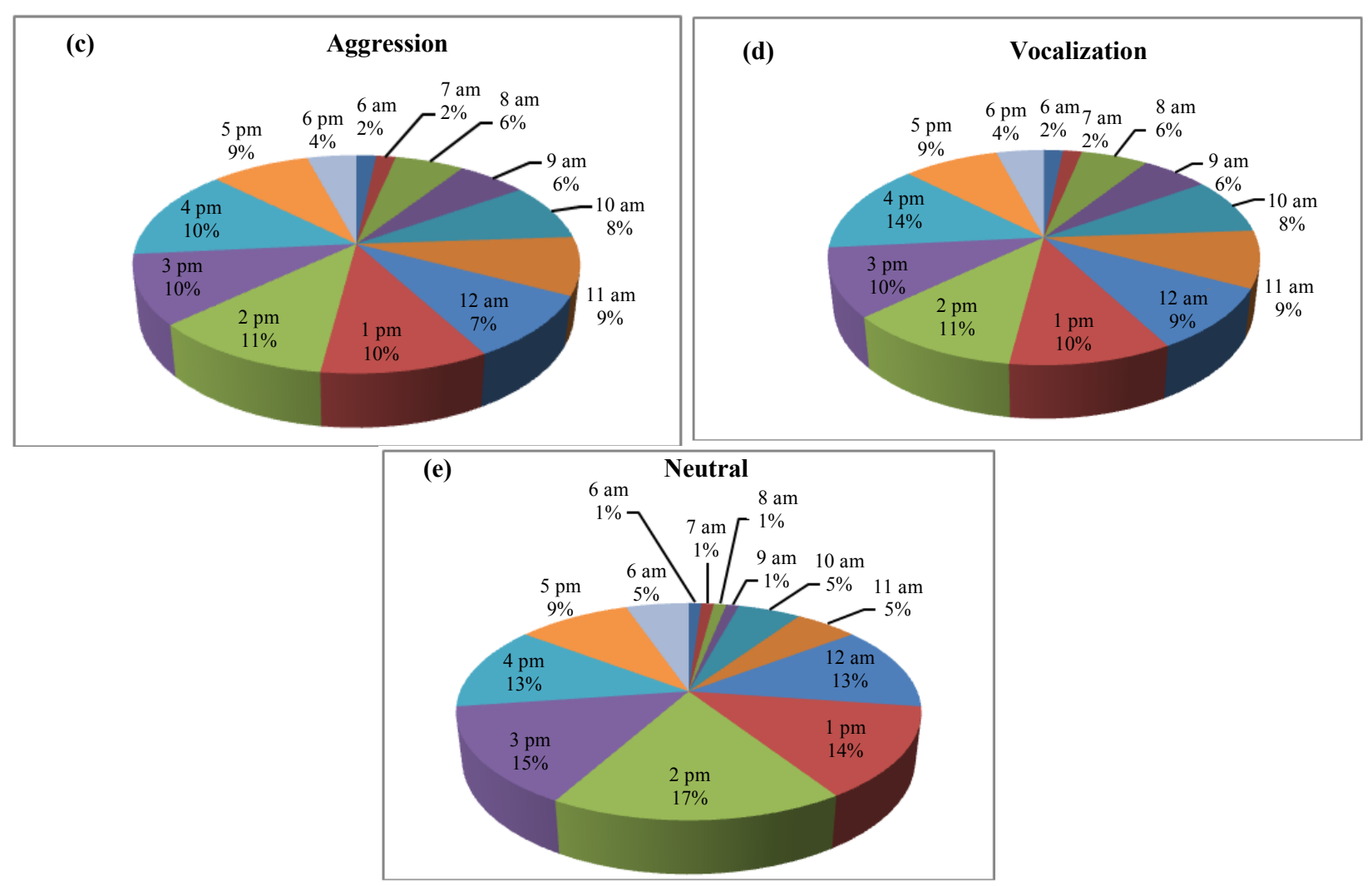

Fig. 5(a-e): Frequency percentage of behavior between macaque and human: (a) Food-related interaction, (b) Conflicting, (c) Aggression, (d) Vocalization and (e) Neutral at different period of a day

\section{Discussion}

Based on data in the study, our survey indicated a density of macaque population and their behavior all day of seven macaque groups in the old town area, Lopburi. The total count method by photography was suitable in Lopburi due to easily finding and identifying animals (Plumptre et al., 2013). The observed monkeys were well habituated to human allowing the observer without disturbing any behavior. Average macaque group size falled in the range 70-700 individual/groups. There were similar reports that showed group size of long-tailed macaques exceeded 70 individuals (Sussman et al., 2011) and 100 individuals (Gumert et al., 2011). Group sizes in this study rather close to number when compare to previously denoted by Watanabe et al. (2007) and preliminary results of Malaivijitnond and Hamada (2008). In 2007, five macaque groups located in the old city area in and around Prang Sam Yot was recorded by Watanabe et al. (2007). In preliminary observations of Malaivijitnond and Hamada (2008) at Lopburi, revealed that the largest group used two shrines and adjacent school grounds (400-450 individuals). Another group was based at an abandoned Malai Rama Theater behind Prang Sam Yot (110-150 individuals). The third group was concentrated around the fire station including Manora Market (140-190 individuals). The fourth large group (180-240 individuals) resided directly south of the Prang Sam Yot shrine on residential buildings and Sri Indra Hotel. The fifth and smallest troop was usually found near the Prang Khaek shrine (70-80 individuals). Preliminary counts suggested that there were approximately 900-1,150 individuals in the old city area. However, interview answers regarding the macaque population in Lopburi showed that people personally estimated a larger number range between 1,500-4,000. The long-tailed macaque population at old town, Lopburi and nearby areas was increased when compared to all of previous reports. The vary group sizes and overlapping area using of observed long-tailed macaques was found in this study support by the report of Menard (2004) and Md-Zain et al., 2010). The number of animals in the studied groups was not allowed to migrant to the other groups. However, there was a report of dispersing long-tailed macaques into other groups (Oi, 1990).

The monkeys in Lopburi Province are traditionally regarded as sacred and honored creatures that stay in the vicinity of Shrine in the old town area. Problems caused by the macaques will get worse as the abundance of macaques in old town areas increases. The macaques are more concentrated in the downtown areas including along the street and railway station because of feeding by 
human in this area. In addition, the indigenous people made a holy ritual by feeding macaque nearby the shrine. The macaque population control strategy at Lopburi old town is not launch properly.

Food supply for macaques had influence the amount of time spent for other behaviors in each day. An increase in feeding behavior was caused a decrease in other behavior. A large portion of daily activity budget for all study groups was feeding and inactive behaviors. The result was contrast to other studies by Md-Zain et al., (2010; Hambali et al., 2012). Those reports showed locomotion was the highest of daily activity for longtailed macaques. The long- tailed macaques moving behavior was less than the other study due to easily searching for food in the urban ecosystem. As long-tailed macaques adapt to the modified urban building habitat and stay commensally with human in the old town which has no enough space for movement. The lower habitat quality of the city environment causes long-tailed macaques spend most of the time for inactive behavior.

The macaques-tourists interactions in the old town, Lopburi showed more close contact than macaqueslocals interactions. These observations are similar to those made by Fuentes (2006) when he observed differences between types of people and the interactions between humans and macaques at Bali and Gibraltar. In addition, work in Singapore has shown that residents and visitors to nature parks with macaques have very different attitudes and very different experiences with macaques (Sha et al., 2009b). Studying the behavioral flexibility and adaptability of wild and human- altered habitats of Assamese macaques (M. assamensis) in the in central Nepal also showed that provisioning alters the activity and feeding behavior of macaques. Moreover, it can increase human-macaque conflict and disease transmission (Koirala et al., 2017).

Long-tailed macaques have several negative impacts on humans. Macaques compete with humans for food and space and can be threatening to humans in their proximity. Macaques can parasitize human resources, damage dwellings and access refuse, causing the spread of debris within a community (Gumert et al., 2011). They also occasionally threaten or cause harm to humans by acting aggressively. Aggressive macaque-to-human behavior is mainly the result of direct competition over contestable food sources (Fuentes, 2006; Fuentes et al., 2008; Sha et al., 2009b), but can also occur due to human prompting (i.e., teasing, chasing, approaching to close, etc.), defense of young and interference with mating activity ((McCarthy et al., 2009; Gumert et al., 2009). A potential negative consequence is the spread of infections, which has become a special concern because of the close biological similarity of macaques and humans (Gumert et al., 2011). Human populations significantly affect macaques in negative ways. Human caused habitat alteration can attract macaques to human settlements and humans are highly interested in feeding macaques, which cause behavioral changes in them. Human-fed macaques learn over time to venture further into human settlement and lose their fear of being in close proximity and contact of people (i.e., loss of flight distance). Sustained feeding by humans can also alter the reproductive success of macaques, by lowering infant and juvenile mortality and thus increasing population growth (Gumert et al., 2011). In contrast, humans can also limit population growth because they are dangerous to macaques and can harm or kill them through their activity, such as hunting, trapping (Louden et al., 2006), culling and removal of macaques (Gumert et al., 2011; Sha et al., 2009a; 2009b). Areas of macaque-human interface range from highly competitive to mutualistic. In regions of great competition, human-macaque conflict is very high causing stress to both species and generating the general sense that solutions are needed to ameliorate the situation. Consequently, strategies and management plans need to be developed and enacted in order to remedy some of the problems occurring in human-macaque interface zones. The management of respective locales was recommended to formulate practical strategies to avoid or decrease the interaction between both.

All the food was provided by humans either directly or indirectly to the monkeys everywhere by leaving food items in monkey reach ranges. The macaques do not have to trouble themselves in searching for food. However, food management especially nutrient is imperative for Lopburi macaques which receiving unsuitable feed. The tourists like to feed the macaques and this can lead to the macaques feeling safe/habituating to humans and explore nearby human residential areas/building and so result in the increase in macaque's population level and residential humanmacaque interactions and disturbances. Poor maintenance of garbage collection will also contribute to the increased interference levels of macaques in human residential areas. The purpose of the survey was in part to obtain behavior information in order to select the effective method to manage the undesirable behavior of macaques and the human macaque interactions in the Lopburi province in the future. Nowadays, the translocation plan of nuisance monkey and vasectomy was done during 2015. The continuous stream of activity/behavior of long tailed macaque in Lopburi urban ecosystem is important in conservation planning and benchmarking in other urban environments.

\section{Conclusion}

The population of long tailed macaques in the old town of Lopburi province and nearby areas was significantly increased when compared to all of the previous reports. The macaques are more easily seen in the downtown areas including the roadsides and railway station because they are always fed by people in this area. Food supply for macaques had an apparent 
influence on the amount of time spent on their daily behaviors. The information in terms of population and behaviors could be further useful for management planning of human-macaque interactions in the Lopburi urban ecosystem in the future.

\section{Funding Information}

This work was supported by the Office of Lopbui province, Thailand (300/2557).

\section{Author's Contributions}

Duangjai Boonkusol: Coordinated the implementation of research work, conducted research, compiled the literary review, analyzed and interpreted the study findings, drew conclusions, contributed manuscript preparation and revisions.

Pornchai Sanyathitiseree: Conducted research, compiled the literary review, analyzed and interpreted the results, contributed manuscript revisions.

Suporn Thongyuan: Conducted research, contributed manuscript revisions.

Nantana Jangsuwan: Designed research study, provided leadership and coordinated the implementation of research work.

\section{Conflict of Interest}

The authors declare no conflict of interest.

\section{References}

Aggimarangsee, N., 1992. Survey for semi-tame colonies of macaques in Thailand. Nat. Hist. Bull. Siam Soc., 40: 103-166.

Altmann, J., 1974. Observational study of behavior: Sampling methods. Behaviour, 49: 227-266.

Defler, T.R. and D. Pintor, 1985. Censusing primates by transect in a forest of known primate density. Int. J. Primatol., 6: 243-259.

Fooden, J., 1971. Report on primates collected in western Thailand January-April, 1967. Fieldiana Zool., 59: 1-62.

Fooden, J., 1995. Systematic review of Southeast Asia longtail macaques, Macaca fascicularis (Raffles, 1821). Fieldiana Zool., 81: 1-206.

Fuentes, A., 2006. Human culture and monkey behavior: Assessing the contexts of potential pathogen transmission between macaques and humans. Am. J. Primatol., 68: 880-896.

Fuentes, A., S. Kalchik, L. Gettler, A. Kwiatt and M. Konecki et al., 2008. Characterizing humanmacaque interactions in Singapore. Am. J. Primatol., 70: 879-883.
Gumert, M.D., A. Fuentes and L. Jones-Engel, 2011. Monkeys on the Edge: Ecology and Management of Long-tailed Macaques and Their Interface with Humans. Cambridge University Press, Cambridge, ISBN: 9781139500418 , Pages: 380.

Gumert, M.D., M. Kluck and S. Malaivijitnond, 2009. The physical characteristics and usage patterns of stone axe and pounding hammers used by long tailed macaques in the Andaman sea region of Thailand. Am. J. Primatol., 71: 594-608.

Hambali, K., A. Ismail and B.M. Md-Zain, 2012. Daily activity budget of long-tailed macaques (Macaca fascicularis) in Kuala Selangor nature park. Int. J. Basic Applied Sci., 12: 47-52.

Koirala, S., M.K. Chalise, H.B. Katuwal, R. Gaire and B. Pandey et al., 2017. Diet and activity of Macaca assamensis in wild and semi-provisioned groups in Shivapuri Nagarjun national park, Nepal. Folia Primatol., 88: 57-74.

Louden, J.E., M.E. Howells and A. Fuentes, 2006. The importance of integrative anthropology: A preliminary investigation employing primatological and cultural anthropological data collection methods in assessing humanmonkey co-existence in Bali Indonesia. Ecol. Environ. Anthropol., 2: 2-13.

Malaivijitnond, S. and Y. Hamada, 2008. Current situation and status of long-tailed macaques (Macaca fascicularis) in Thailand. Trop. Nat. Hist., 8: 185-204.

Malaivijitnond, S., N. Urasopon, S. Goto and Y. Hamada, 2009. Diversity study of primates in Thailand. Proceedings of the 2nd International Symposium on Southeast Asian Primate Research, Biodiversity Study of Primates in Laos, Jan. 22-23, National University of Laos, Laos.

Malaivijitnond, S., Y. Hamada, P. Varavudchi and O. Takenaka, 2005. The current distribution and status of macaques in Thailand. Nat. Hist. J. Chulalongkorn Univ., 1: 35-45.

McCarthy, M.S., M.D. Matheson, J.D. Lester, L.K. Sheeran, J.H. Li and R.S. Wagner, 2009. Sequences of Tibetan macaque (Macaca thibetana) and tourist behaviors at Mt. Huangshan, China. Primate Conserv., 24: 145-151.

Md-Zain, B.M., N.A. Sha'ari, M. Mohd-Zaki, F. Ruslin and N.I. Idris et al., 2010. A comprehensive population survey and daily activity budget on longtailed macaques of Universiti Kebangsaan Malaysia. J. Biol. Sci., 10: 608-615.

Menard, H., 2004. Do Ecological Factors Explain Variation in Social Organization? In: Macaque Societies: A Model for the Study of Social Organization,Thierry, B., M. Singh and W. Kaumanns (Eds.). Cambridge University Press, Cambridge, ISBN: 9780521818476, pp: 237-262. 
Oi, T., 1990. Patterns of dominance and affiliation in wild pigtailed macaques (Macaca nemestrina nemestrina ) in West Sumatra. Int. J. Primatol., 11: 339-356.

Perveen, F., R. Karimullah and S. Anuar, 2014. Longtailed macaques Macaca fascicularis (Primate: Cercopithecidae): Human-monkey behavioural interaction in Botanical Gardens Penang, Malaysia. Ann. Exp. Biol., 2: 36-44.

Plumptre, A.J., E.J. Sterling and S.T. Buckland, 2013. Primate Census and Survey Techniques. In: Primate Ecological and Conservation, Sterling, E.J., N. Bynum and M. Blair (Eds.). Oxford University Press, Oxford, ISBN: 9780199659449, pp: 10-26.

Sha, C.M.J., M. Gumert, P.Y.H. Lee, A. Fuentes, S. Rajathurai, K.L. Chan and L. Jones-Engel, 2009a. Status of the long-tailed macaque Macaca fascicularis in Singapore and implications for management. Biodiversity Conserv., 18: 2909-2926.

Sha, J.C., M.D. Gumert, B.P. Lee, L. Jones-Engel, S. Chan and A. Fuentes, 2009b. Macaque-human interactions and the societal perceptions of macaques in Singapore. Am. J. Primatol., 71: 825-839.
Sussman, R.W., C.A. Shaffer and L. Guidi, 2011. Macaca fascicularis in Mauritius: Implications for MacaqueHuman Interactions and for Future Research on Long-Tailed Macaques. In: Monkeys on the Edge: Ecology and Management of long-Tailed Macaques and their Interface with Humans, Gumert, M.D., A. Fuentes and L. Jones-Engel (Eds.). Cambridge University Press, Cambridge, pp: 207-235.

Watanabe, K., N. Urasopon and S. Malaivijitnond, 2007. Long tailed macaques use human hair as dental floss. Am. J. Primatol., 69: 940-944.

Wheatley, B. and D.K.H. Putra, 1994. The effects of tourism on conservation at the monkey forest in Ubud, Bali. Revue D'Ecologie (Terre et la Vie), 49: 245-257.

Wheatley, B. and D.K.H. Putra, 1995. Hanuman, the monkey god, leads conservation efforts in Balinese monkey forest at Ubud, Indonesia. Primate Rep., 41: 55-64. 